Research Article

\title{
Formulation of Mefenamic Acid Loaded Ethosomal Gel by Hot and Cold Methods
}

\author{
Regunta Supraja, Abbaraju Krishna Sailaja \\ RBVRR Women's College of Pharmacy, Osmania University, Hyderabad, India. \\ Corresponding author. E-mail: shailaja1234@rediffmail.com
}

Received: Feb. 27, 2017; Accepted: Mar. 16, 2017; Published: Mar. 23, 2017.

Citation: Regunta Supraja, Abbaraju Krishna Sailaja, Formulation of Mefenamic Acid Loaded Ethosomal Gel by Hot and Cold Methods. Nano Biomed. Eng., 2017, 9(I): 27-35.

DOI: $10.5101 /$ nbe.v9i1.p27-35.

\begin{abstract}
The aim of the present study is the formulation of mefenamic acid ethosomal gel by hot and cold methods. To prepare the mefenamic acid transdermal gel, ethosomes was selected as colloidal carriers. Ethosomes were prepared by cold and hot methods. The obtained ethosomes were characterized with vesicular diameter, zeta potential, drug content, entrapment efficiency and in-vitro diffusion studies. The five formulations of ethosomes prepared by cold and hot methods were compared. Among the 10 formulations of ethosomes, E5 was considered as the best formulation because of its mean vesicular diameter of $854 \mathrm{~nm}$, zeta potential of $20 \mathrm{mV}$, drug content of $96.3 \%$, entrapment efficiency of $94.4 \%$, sustained drug release for $12 \mathrm{hr}$, i.e. 94.4. Then the E5 formulations was incorporated into gel. A comparative study was made between the plain gel and the ethosomal gel. The Ethosomal gel was considered the best because of its highest drug content spreadability , $\mathrm{pH}(6.9)$ and the sustained drug release profile for $12 \mathrm{hr}$. By comparison, the cold method shows better results.
\end{abstract}

Keywords: Mefenamic acid; Ethosomes; Transferosomes; Stability; Vesicular diameter; Entapment efficiency

\section{Introduction}

Transdermal drug delivery system can be used as an alternative delivery of drug into the systemic circulation. Transdermal drug delivery offers many advantages as compared to traditional drug delivery. It is a better alternative to achieve constant plasma levels for prolonged periods of time, which additionally could be advantageous because of less frequent dosing regimens $[1,2]$. These systems include the use of physical means, such as iontophoresis, sonophoresis, microneedles, etc., chemical means like penetration enhancers and biochemical means using liposomes, niosomes, transferosomes and ethosomes. They also have been reported to enhance the permeability of drug through the stratum corneum. The vesicles have been well known for their importance in cellular communication and particle transportation for many years. Researchers have understood the properties of the vesicle structure for use in better drug delivery within their cavities, which would tag the vesicle for cell specificity $[3,4]$. One of the major advances in vesicle research was the finding of a vesicle derivative, known as ethosomes. The ethosomal system is composed of phospholipid, high concentration of alcohol and water. The high concentration of ethanol makes ethosomes unique, because ethanol causes the disturbance of skin lipid bilayer organization. 
Hence, when incorporated into a vesicle membrane, it enhances the vesicles' ability to penetrate the stratum corneum $[5,6]$.

Mefenamic acid (MA) is a non-steroidal antiinflammatory drug (NSAIDS) that exhibits antiinflammatory and analgesic activities. It is a BCS class-2 drug. It is available in the forms of tablets, capsules and suspension. MA has a wide range of gastrointestinal disorders, such as gastrointestinal bleeding \& gastric upset. It has poor solubility over the $\mathrm{pH}$ range of 1.2-7.5. The biological half-life of $\mathrm{MA}$ is 2-4 hr. MA causes COX-1 and COX-2 inhibition. By inhibiting COX-1 receptors, it causes severe gastric bleeding and peptic ulcers. By inhibiting COX-2 receptors, it causes severe cardiovascular side effects. Because of the short half-life, frequent administration of the drug is required which may lead to missing the dose of the drug and thus under medication. Hence, formulating mefenamic acid loaded ethosomes can minimize the dose, the dosing frequency and the side effects. There is no transdermal formulation of mefenamic acid available to date as per literature review $[7,8]$.

\section{Materials and Methods}

\section{Formulation of mefenamic acid loaded ethosomes by cold method}

According to this method, the required amount of soya lecithin and drug were taken, a few ml of ethanol was added, and then it was kept for magnetic stirring. During the stirring, small quality of propylene glycol was added; the temperature and the speed were maintained at $30{ }^{\circ} \mathrm{C}$ and $700 \mathrm{RPM}$ for $20 \mathrm{~min}$. In another phase, distilled water was heated at $30{ }^{\circ} \mathrm{C}$. This aqueous phase was added to organic phase. This mixture was stirred for another $5 \mathrm{~min}$ which led to the formulation of ethosomes. The formulation was stored under refrigeration. Five formulations were prepared by varying the drug and soya lecithin concentration [11, 12] (Table 1).

Table 1 List and composition of formulations prepared by cold method

\begin{tabular}{ccccc}
\hline No. & $\begin{array}{c}\text { Formulation } \\
\text { code }\end{array}$ & $\begin{array}{c}\text { Drug: } \\
\text { soya lecithin }\end{array}$ & $\begin{array}{c}\text { Propylene } \\
\text { glycol }(\mathrm{ml})\end{array}$ & Ethanol (ml) \\
\hline 1 & E1 & $1: 1$ & 1 & 2 \\
2 & E2 & $1: 1.5$ & 1 & 2 \\
3 & E3 & $1.5: 1$ & 1 & 2 \\
4 & E4 & $1: 2$ & 1 & 2 \\
5 & E5 & $2: 1$ & 1 & 2 \\
\hline
\end{tabular}

\section{Formulation of mefenamic acid loaded ethosomes by hot method}

According to this method, phospholipid and mefenamic acid were dispersed in water by heating in a water bath at $40{ }^{\circ} \mathrm{C}$ until a colloidal solution was obtained. Ethanol, propylene glycol and drug were mixed in a separate vessel and heated up to $40{ }^{\circ} \mathrm{C}$. Organic phase was added to aqueous phase and stirred for $5 \mathrm{~min}$ at $700 \mathrm{rpm}$ on a magnetic stirrer. The vesicle size of ethosomal formulation was decreased to the desired extent using sonication. Finally, the formulation was properly stored at $4{ }^{\circ} \mathrm{C}$. Five formulations were prepared by varying the soya lecithin concentration and percentage volume of ethanol $[9,10]$ (Table $2 \& 3$ ).

Table 2 List and composition of formulations prepared by hot method

\begin{tabular}{ccccc}
\hline No. & $\begin{array}{c}\text { Formulation } \\
\text { code }\end{array}$ & $\begin{array}{c}\text { Drug (w/v): } \\
\text { phospholipid } \\
\%(\mathrm{w} / \mathrm{v})\end{array}$ & $\begin{array}{c}\text { Propylene } \\
\text { Glycol (ml) }\end{array}$ & Ethanol (ml) \\
\hline 6 & E6 & $1: 1$ & 1 & 2 \\
7 & E7 & $1: 1.5$ & 1 & 2 \\
8 & E8 & $1.5: 1$ & 1 & 2 \\
9 & E9 & $1: 2$ & 1 & 2 \\
10 & E10 & $2: 1$ & 1 & 2 \\
\hline
\end{tabular}

Table 3 Parameters optimized for the preparation of mefenamic acid ethosomes by hot method

\begin{tabular}{ccc}
\hline Optimized parameters & Formulation variables & Constant parameters \\
\hline & & Soya lecithin; \\
& $300 \mathrm{rpm}$ & Ethanol; \\
Stirring speed (rpm) & $500 \mathrm{rpm}$ & Propylene glycol; \\
& $700 \mathrm{rpm}$ & Drug; \\
& & Heating temperature \\
& $40{ }^{\circ} \mathrm{C}$ & Cholesterol; \\
Heating temperature & & Soya lecithin; \\
& & Drug; \\
& & Rotation speed \\
\hline
\end{tabular}

\section{Results and Discussion}

\section{Mefenamic acid loaded ethosomes using cold method}

Process parameters such as stirring speed and heating temperature were optimized at $500 \mathrm{rpm}$ and $30{ }^{\circ} \mathrm{C}$ respectively. By varying the drug ratio of, soya lecithin, five formulations E1, E2, E3, E4 and E5 were prepared. From the results it was found that mean vesicular diameter of all five formulations was in nano-range. They were characterized and evaluated in order to determine the best formulation for the preparation of mefenamic acid loaded ethosomes by 

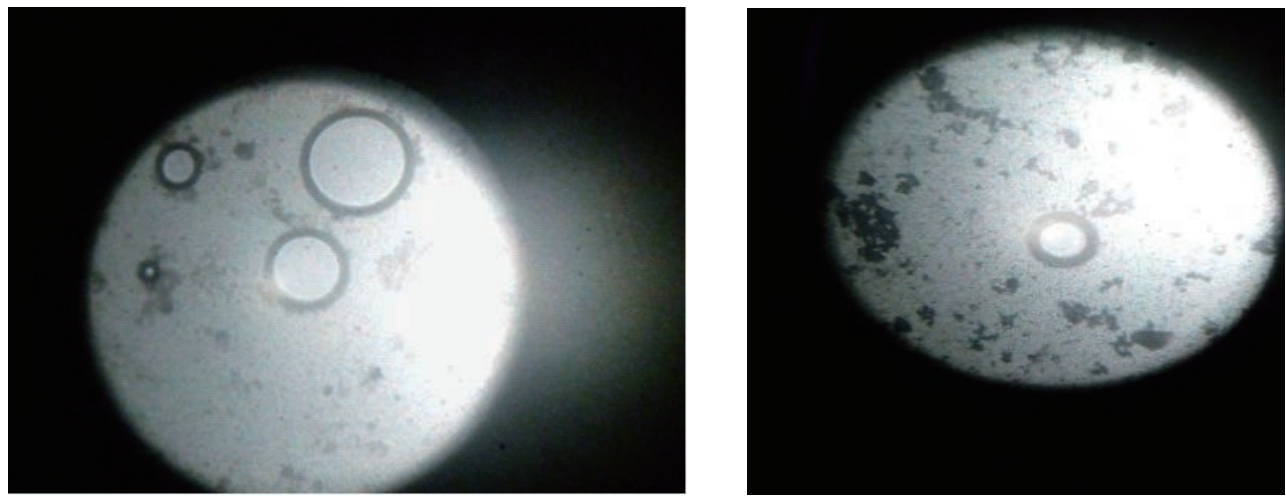

Fig. 1 Photomicrographic images of E5 formulation of mefenamic acid loaded ethosomes prepared by cold method (magnification $10 \times)$.

cold method $[13,14]$.

\section{Optical microscopy}

Morphology was determined for all the five formulations using optical microscopy (S-3700N, Hitachi, Japan) $[15,16]$. The photo micrographic pictures of the preparation were obtained from the microscope by using a digital SLR camera (Fig. 1).

\section{Vesicle diameter}

The prepared five formulations were characterized for particle size using Zetasizer (Malvern Instruments Ltd) $[17,18]$. The analysis was performed at a temperature of $25{ }^{\circ} \mathrm{C}$ with double distilled water as dispersion medium (Fig. 2).

All five formulations were in nano-size range. The mean vesicular diameters of E1, E2, E3, E4 and E5 formulations were found to be $374 \pm 2,362 \pm 3,359$ $\pm 2,472 \pm 4$ and $480 \pm 3 \mathrm{~nm}$ respectively. Among all the formulatins E3 formulation was showing minimum

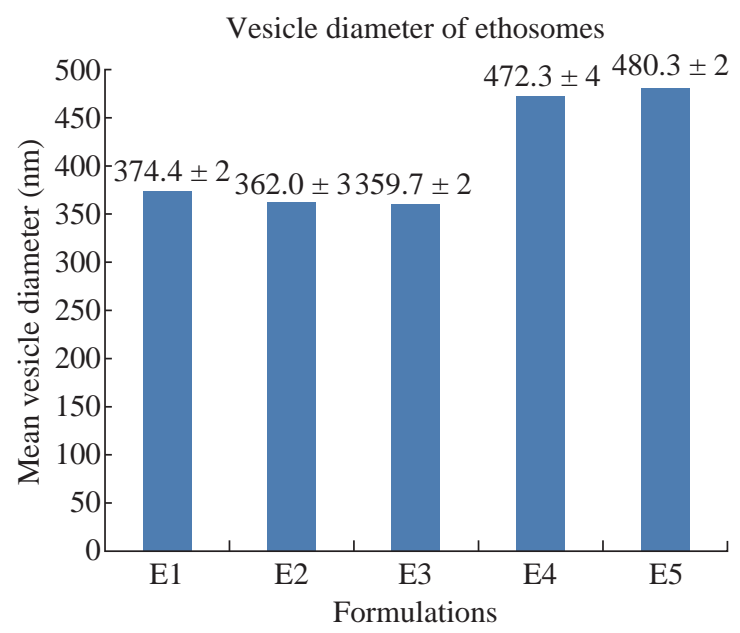

Fig. 2 Comparison of mean vesicular diameters of five formulations of mefenamic acid ethosomes prepared by cold method. vesicular diameter.

\section{Zeta potential}

The prepared five formulations were characterized for zeta potential value in order to know the stability of the formulations. The analysis was performed at a temperature of $25{ }^{\circ} \mathrm{C}$ with double distilled water as dispersion medium $[19,20]$. From the results all the formulations were found to be stable (Fig. 3).

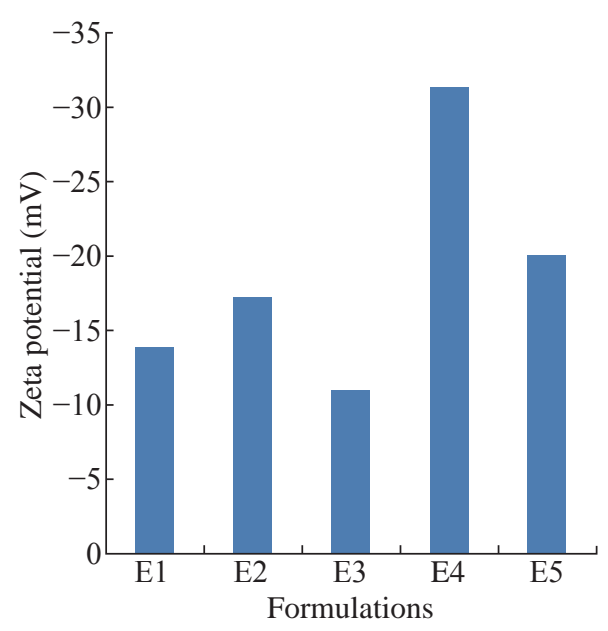

Fig. 3 Comparison of zeta potential values of five formulations of mefenamic acid ethosomes prepared by cold method.

From the results all the formulations were found to be stable. The zeta potential values of E1, E2, E3, $\mathrm{E} 4$ and $\mathrm{E} 5$ formulations were found to be $-13.3 \pm 0.5$, $-17.2 \pm 0.4,-11.2 \pm 1,-31.3 \pm 2$ and $-20.1 \pm 1 \mathrm{mV}$ respectively. Among all formulations E4 formulation was showing highest zeta potential value with greater stability of $-31.1 \mathrm{mV}$.

\section{Drug content}

The prepared five formulations were evaluated for drug content. 
Drug content of E1, E2, E3, E4 and E5 formulations was found to be $58.35 \pm 3,53.50 \pm 2,47.14 \pm 4,64.94$ \pm 4 and $96.34 \pm 5 \%$ respectively. E5 formulation containing the $2: 1$ ratio of drug : phospholipid was considered the best formulation because of its highest drug content of $96.34 \%$ (Fig. 4).

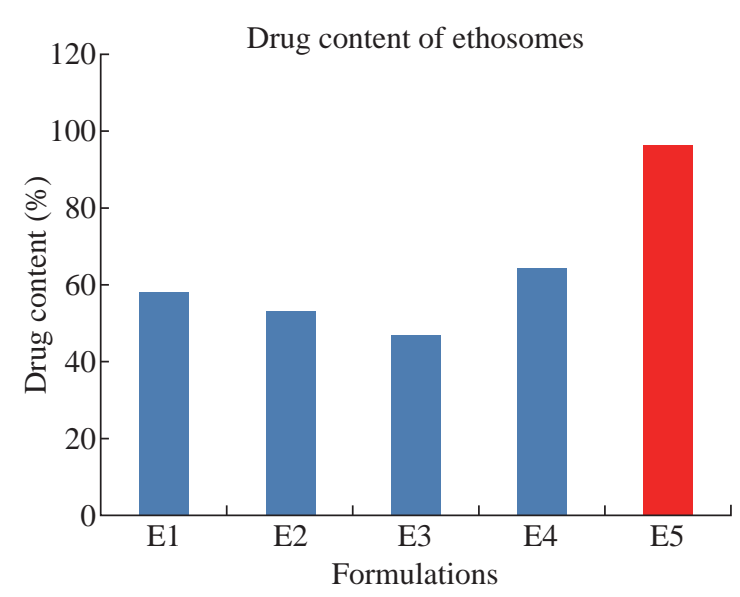

Fig. 4 Comparison of drug content among the five formulations of mefenamic acid loaded ethosomes prepared by cold method.

\section{Entrapment efficiency}

All the five formulations were evaluated for drug entrapment efficiency using cooling ultra-centrifuge (Eltek, Mumbai) [21] (Fig. 5).

The percentages of drug entrapment efficiency of E1, E2, E3, E4 and E5 formulations were found to be $87.2 \pm 3,84.1 \pm 4,93.38 \pm 4,89.44 \pm 3$ and $94.4 \pm 5 \%$ respectively. From the results the highest percentage of entrapment efficiency $94.4 \%$ was observed for $2: 1$ ratio of drug to phospholipid, ie. formulation E5. The

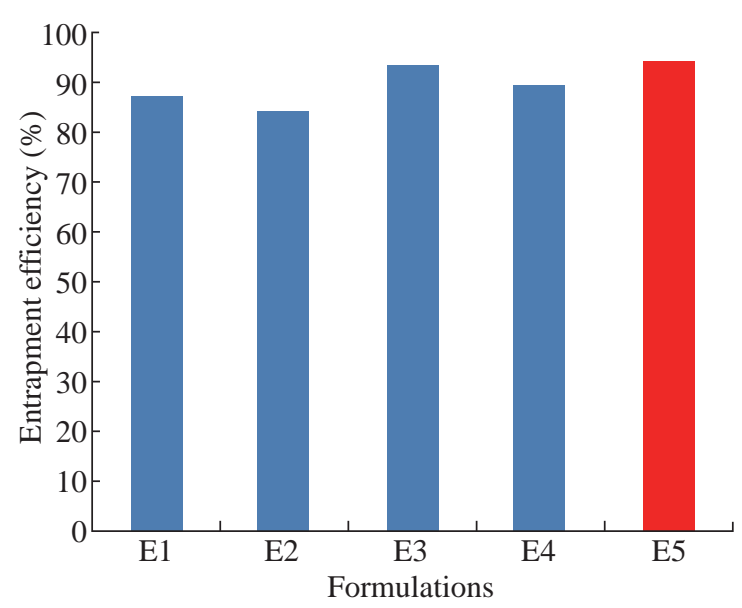

Fig. 5 Comparison of drug entrapment efficiency among five formulations of mefenamic acid loaded ethosomes prepared by cold method. ethosomes prepared using drug: soya lecithin at $2: 1$ ratio showed higher entrapment efficiency. Further increasing soya lecithin concentration decreased the entrapment efficiency.

\section{Comparison of in-vitro drug diffusion study data of mefenamic acid loaded ethosomes}

All the five formulations were evaluated for in-vitro drug diffusion studies using Franz diffusion cell. Invitro drug release studies were conducted for a time period of $12 \mathrm{hr}$ (Fig. 6).

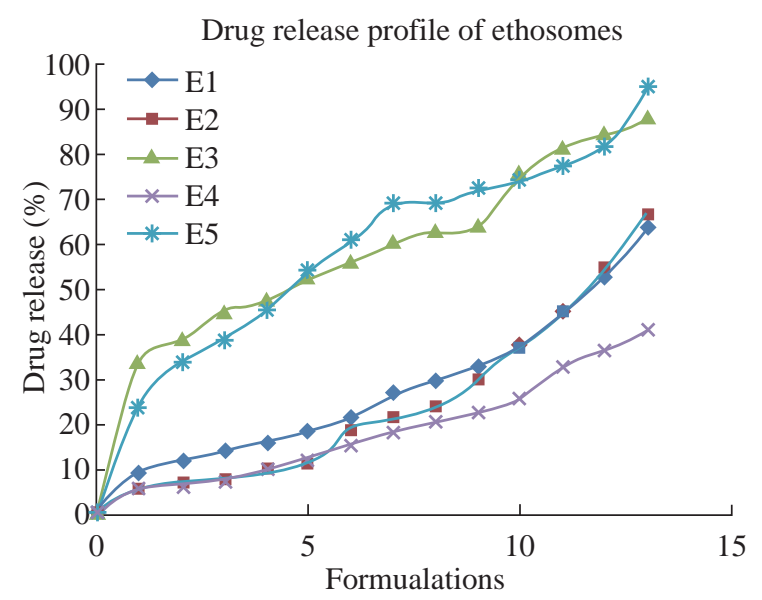

Fig. 6 Comparison of in-vitro drug diffusion studies among the five formulations of mefenamic acid loaded ethosomes prepared by cold method.

From the data it was observed that E5 formulation containing 2:1 ratio of drug to soya lecithin formulation showed a sustained release up to $12 \mathrm{hr}$ with drug release of $94.4 \%$.

In ethosomal formulations, the experimental studies showed that the rate of drug release depends on the percentage of drug entrapment efficiency. From the five ethosomal formulations E5 showed more sustained drug release than other formulations. Hence, it was considered as the best ethosomal formulation.

\section{Ethosomes prepared by hot method}

A general procedure based on the literature was followed for the preparation of mefenamic acid ethosomes. The process variables were optimized to yield mefenamic acid ethosomes with smaller mean particle diameter, good stability and higher entrapment efficiency.

By varying the drug: soya lecithin ratio, five formulations E6, E7, E8, E9 and E10 were prepared. From the results it was found that the sizes of all 

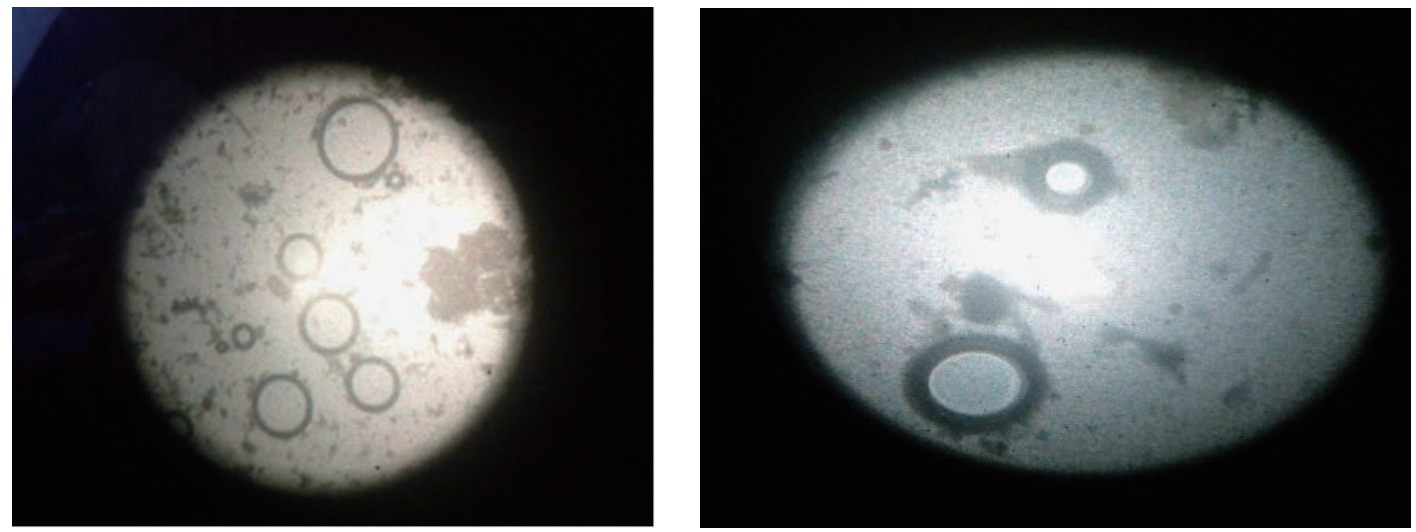

Fig. 7 Photomicrographic images of E6 formulation of mefenamic acid loaded ethosomes prepared by hot method (magnification $10 \times)$.

five formulations were in optimum range. They were characterized and evaluated in order to determine the best formulation for the preparation of mefenamic acid loaded ethosomes by hot method.

\section{Optical microscopy}

Morphology was determined for all the five formulations using optical microscopy (S-3700N, Hitachi, Japan). The photo micrographic pictures of the preparation were obtained from the microscope by using a digital SLR camera (Fig. 7).

\section{Particle size distribution}

The prepared five formulations were characterized for mean vesicular diameter using Zetasizer (Malvern Instruments Ltd). The analysis was performed at a temperature of $25{ }^{\circ} \mathrm{C}$ with double distilled water as dispersion medium (Fig. 8).

All five formulations were in nano-size range. The

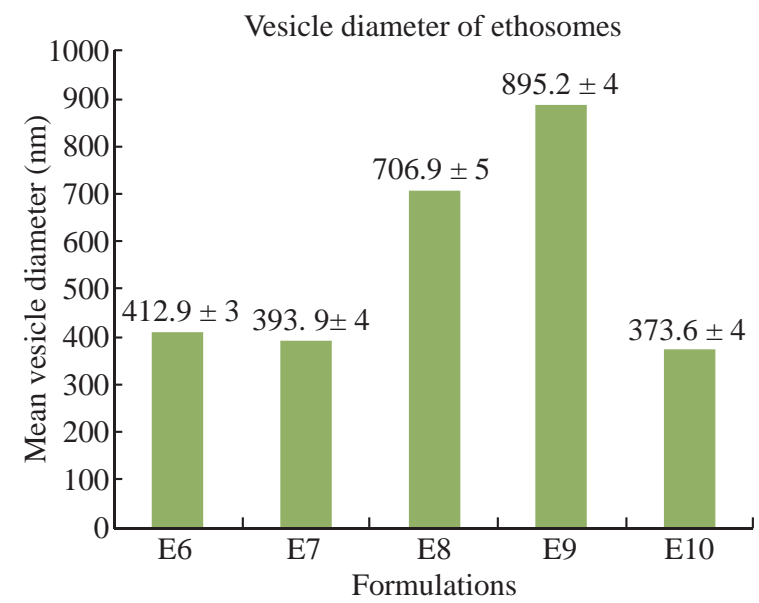

Fig. 8 Comparison of mean vesicular diameter of five formulations of mefenamic acid ethosomes prepared by hot method. mean vesicular diameters of E6, E7, E8, E9 and E10 formulation were found to be $412.9 \pm 3,393.9 \pm 4$, $706.9 \pm 5,895.2 \pm 4$ and $373.6 \pm 5 \mathrm{~nm}$ respectively. Among all formulations E10 was showing minimum vesicular diameter of $373.6 \pm 4 \mathrm{~nm}$ (Fig. 9).

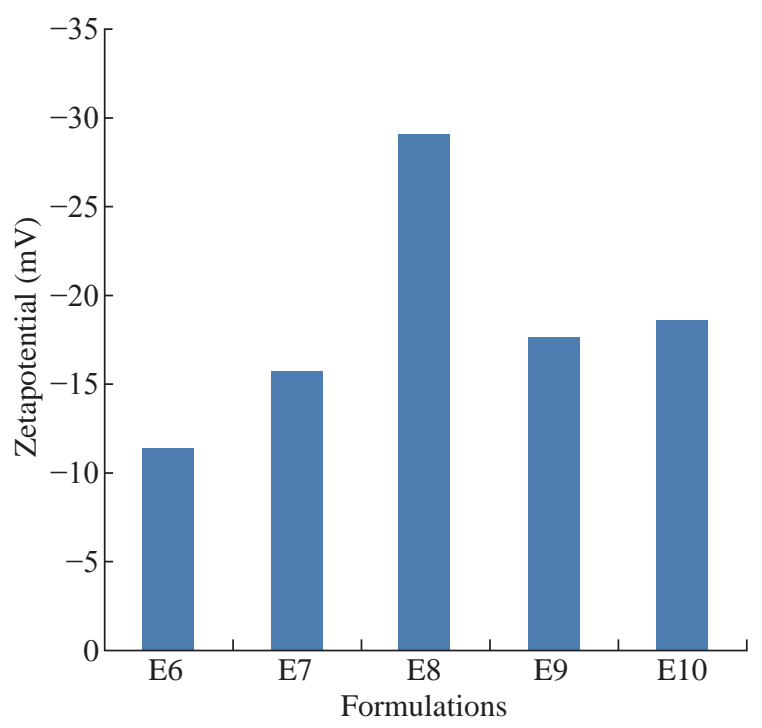

Fig. 9 Comparison of zeta potential values of five formulations of mefenamic acid ethosomes prepared by hot method.

\section{Zeta potential}

The prepared five formulations were characterized for zeta-potential value in order to know the stability of the formulations. The analysis was performed at a temperature of $25{ }^{\circ} \mathrm{C}$ with double distilled water as dispersion medium. From the results all the formulations were found to be stable.

From the results all the formulations were found to be stable. The zeta potential values of E6, E7, E8, E9 and E10 formulation were found to be $-11.4 \pm 2,-15.8 \pm 3$, $-29.1 \pm 2,-17.6 \pm 2$ and $-18.6 \pm 1 \mathrm{mV}$ respectively. 
Among all the five formulations E8 formulation was showing greater stability than other formulations.

\section{Drug content}

The prepared five formulations were evaluated for drug content (Fig. 10).

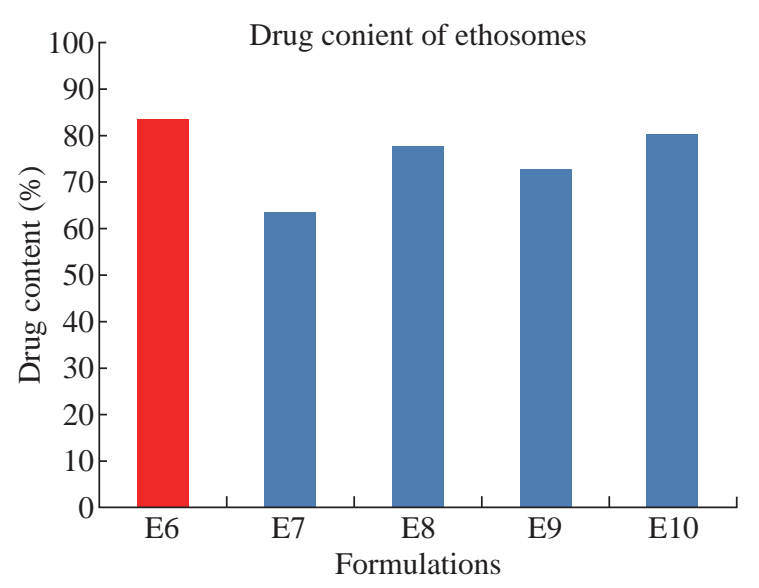

Fig. 10 Comparison of drug content among the five formulations of Mefenamic acid loaded ethosomes prepared by hot method.

Drug content of E6, E7, E8, E9 and E10 formulations was found to be $83.82 \pm 2,63.71 \pm 2,77.84 \pm$ $3,73.05 \pm 3$ and $80.32 \pm 4 \%$ respectively. Out of five formulations, the highest drug content was observed for 1 : 1 ratio of drug to phospholipid formulation E6 with $83.2 \%$.

\section{Encapsulation efficiency}

All the five formulations were evaluated for drug entrapment efficiency using cooling ultra-centrifuge (Eltek, Mumbai) (Fig. 11).

The percentage of drug entrapment efficiency of E6, E7, E8, E9 and E10 formulations was found to be 72.85

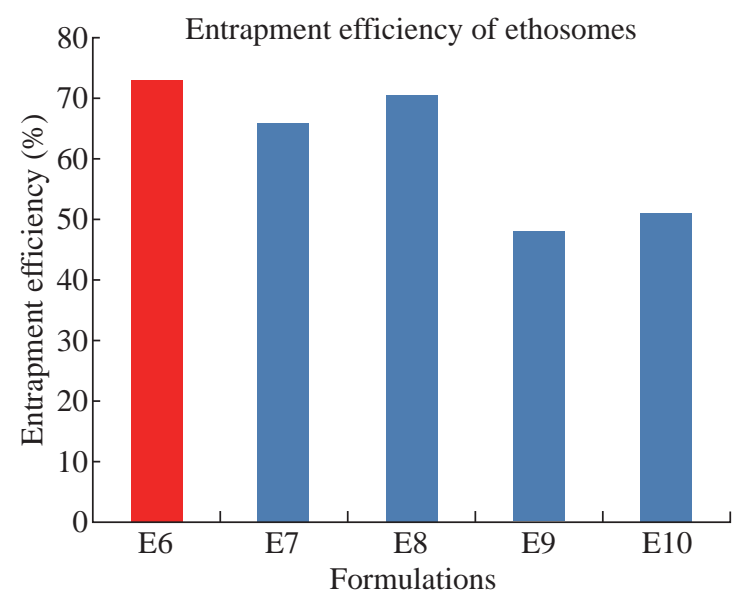

Fig. 11 Comparison of drug entrapment efficiency among five formulations of mefenamic acid loaded ethosomes prepared by hot method. $\pm 2,65.79 \pm 2,70.54 \pm 3,48.03 \pm 3$ and $51.52 \pm 5 \%$ respectively. From the results the highest percentage of entrapment efficiency of $72.85 \%$ was observed for $1: 1$ ratio of drug : phospholipid formulation, ie. E6. The ethosomes prepared using drug : Soyalecithin at $1: 1$ ratio showed higher entrapment efficiency.

\section{Comparison of in-vitro drug diffusion study data of mefenamic acid loaded ethosomes.}

All the five formulations were evaluated for in-vitro drug diffusion studies using Franz diffusion cell. Invitro drug release studies were conducted for a time period of $12 \mathrm{hr}$ (Fig. 12).

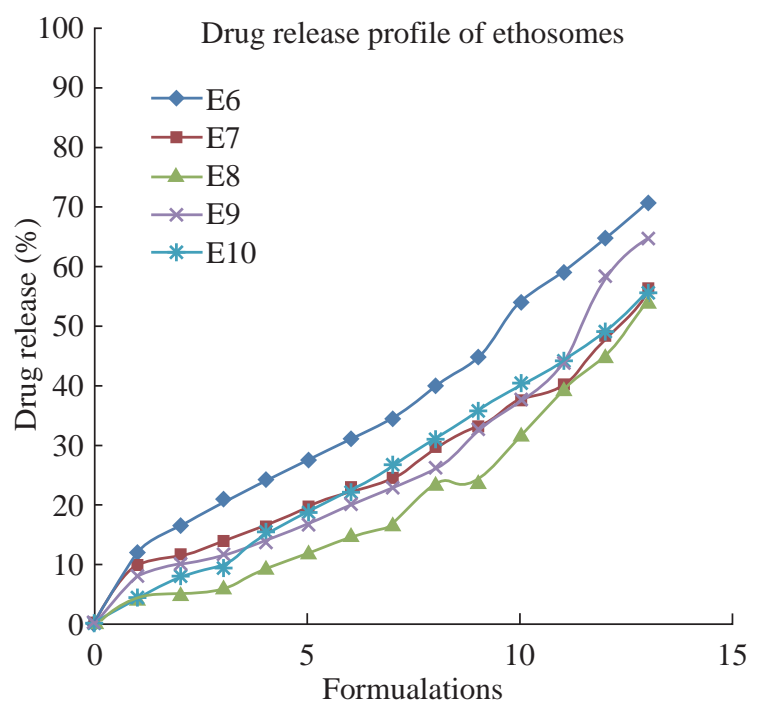

Fig. 12 Comparison of in-vitro drug diffusion studies among the five formulations of mefenamicacid loaded ethosomes prepared by hot method.

From the data it was observed that E6 of $1: 1$ ratio of drug to soya lecithin formulation showed a sustained release profile of $70.31 \%$ for up to $12 \mathrm{hr}$ when compared to other formulations.

In ethosomal formulations, the experimental studies showed that the rate of drug release depends on the percentage of drug entrapment efficiency. Among the five ethosomal formulations, E6 showed more sustained drug release than other formulations. Hence, it was optimized as the best ethosomal formulation.

\section{Comparison between cold method and hot method}

Ethsomes were prepared by cold method and hot method. By comparison, cold method was considered as a preferable method because of its minimum mean vesicular diameter, highest stability, highest 
Table 4 Kinetic data of E5 ethosomal formulations

\begin{tabular}{|c|c|c|c|c|c|c|}
\hline Time (hr) & $\begin{array}{l}\text { Cumulative drug } \\
\text { release }(\%)\end{array}$ & Drug remaining (\%) & $\begin{array}{c}\text { Log drug } \\
\text { remaining (\%) }\end{array}$ & $\mathrm{T} 1 / 2$ & $\log T$ & $\begin{array}{l}\text { Log cumulative } \\
\text { drug release }(\%)\end{array}$ \\
\hline 0.5 & 23.88 & 76.12 & 1.881 & 0.707 & -0.30 & 1.37 \\
\hline 1 & 33.84 & 66.16 & 1.802 & 1 & 0 & 1.529 \\
\hline 2 & 39 & 61 & 1.78 & 1.414 & 0.30 & 1.59 \\
\hline 3 & 43.96 & 56.04 & 1.748 & 1.732 & 0.477 & 1.64 \\
\hline 4 & 50.52 & 49.48 & 1.693 & 2 & 0.602 & 1.703 \\
\hline 5 & 54.32 & 45.68 & 1.659 & 2.236 & 0.698 & 1.734 \\
\hline 6 & 60.44 & 39.56 & 1.597 & 2.449 & 0.778 & 1.781 \\
\hline 7 & 66.56 & 33.56 & 1.524 & 2.645 & 0.845 & 1.82 \\
\hline 8 & 68.72 & 31.28 & 1.495 & 2.828 & 0.903 & 1.83 \\
\hline 9 & 75.16 & 24.84 & 1.395 & 3 & 0.954 & 1.87 \\
\hline 10 & 77.36 & 22.64 & 1.354 & 3.162 & 1 & 1.88 \\
\hline 11 & 84.24 & 15.76 & 1.197 & 3.316 & 1.041 & 1.92 \\
\hline 12 & 94.04 & 5.96 & 0.775 & 3.464 & 1.079 & 1.97 \\
\hline
\end{tabular}

drug content, entrapment efficiency and in-vitro drug release.

\section{Kinetic models for optimized formulation}

Several plots (zero order plot, first order plot, higuchi plot and peppas plots) were drawn for the optimized formulation in order to know the release kinetics and drug release mechanism (Table $4 \& 5$ ).

Table 5 Kinetic data of E5 formulation

\begin{tabular}{ccccc}
\multicolumn{4}{c}{ Table 5 Kinetic data of E5 formulation } \\
\hline Formulation & $\begin{array}{c}\text { Zero order } \\
\text { plot }\left(\mathrm{R}^{2}\right)\end{array}$ & $\begin{array}{c}\text { First order } \\
\text { plot }\left(\mathrm{R}^{2}\right)\end{array}$ & $\begin{array}{c}\text { Higuchi } \\
\text { plot }\left(\mathrm{R}^{2}\right)\end{array}$ & $\begin{array}{c}\text { Peppas } \\
\text { plot }\left(\mathrm{R}^{\mathrm{n}}\right)\end{array}$ \\
\hline FE5 & 0.693 & 0.8532 & 0.9786 & 0.4004 \\
\hline
\end{tabular}

From the results it was concluded that the drug release was following first order kinetics and fitted into korsmeyer equation revealing fickian diffusion mechanism.

\section{Evaluation of plain and ethosomes gel}

\section{Clarity}

Plain gel (PG) and nanobased gel (E5G, T10G) were prepared by simple dispersion technique and evaluated for clarity visually (Table 6).

From the results it was observed that all the formulations were clear.

\section{Measurement of $\mathrm{pH}$}

The formulated plain gel (PG) and nanobased gel
Table 6 Clarity results of PG, E5G and T10G formulations

\begin{tabular}{cc}
\hline Formulations & Clarity \\
\hline PG & +++ \\
E5G & ++ \\
\hline
\end{tabular}

Table $7 \mathrm{pH}$ evaluation of PG, FE5 and FT10 formulations

\begin{tabular}{cc}
\hline Formulations & $\mathrm{pH}$ \\
\hline PG & 6.8 \\
E5G & 6.9 \\
\hline
\end{tabular}

(E5G, T10G) were evaluated for $\mathrm{pH}$ (Table 7).

The $\mathrm{pH}$ of PG, E5G and T10G were found to be 6.8, 6.9 and 7 respectively, calculated in triplicate.

\section{Homogeneity}

All the gel formulations were found to be homogenous and free of aggregates.

\section{Grittiness}

All the formulations were found to fulfil the requirement of freedom from particular matter and from grittiness as desired for any topical preparation .

\section{Drug content}

The percentage drug content of PG, E5G and T10G formulations were evaluated. The percentage drug content of PG and E5G formulations were found to be $94.2 \%$ and $98 \%$ respectively.

\section{Spreadability}

The formulated plain gel (PG) and nanobased gel 
Table 8 Spreadability results of PG and E5G formulations

\begin{tabular}{cc}
\hline Formulations & Spreadability \\
\hline PG & $23.53 \mathrm{~g} \mathrm{~cm} / \mathrm{sec}$ \\
E5G & $33.80 \mathrm{~g} \mathrm{~cm} / \mathrm{sec}$ \\
\hline
\end{tabular}

(E5G) were evaluated for spreadability (Table 8).

\section{In-vitro diffusion studies}

Both the formulations were evaluated for in-vitro diffusion release study using Franz diffusion cell for a period of $12 \mathrm{hr}$. The cumulative percentage drug release of $\mathrm{PG}$ and $\mathrm{E} 5 \mathrm{G}$ formulations were found to be $97.8 \%$ and $79.1 \%$ respectively at the end of $5 \mathrm{hr}$ and $12 \mathrm{hr}$ respectively. E5G formulation was showing more sustained release compared to other formulations, which can be attributed to the higher drug content and greater entrapment efficiency.

\section{Conclusions}

Mefenamic acid is an NSAID which exhibits antipyretic, analgesic and anti-inflammatory activity. The present investigation is the formulation of mefenamic acid transdermal gel based on vesicular drug delivery approaches. Mefenamic acid ethosomes and transferosomes were successfully prepared. Ethosomes were prepared by cold and hot methods..

Five formulations of ethosomes were prepared by cold method by varying the drug to phospholipid concentration ratio. And five formulations of ethosomes were prepared by hot method by varying the concentration drug to phospholipid ratio. All the formuations were characterized for vesicle diameter, zeta potential and evaluated for drug content, entrapment efficiency and in-vitro diffusion studies. Out of ten formulations of ethosomes, E5 formulation of drug : phospholipid at $2: 1$ ratio was found to be the best formulation. In ethosomes, process parameters such as drug: soya lecithin ratio, stirring speed and heating temperature were optimized

By comparing all the formulations of ethosomes, E5 formulation was considered the best formulation because of its smaller mean vesicle diameter (359.7 $\mathrm{nm})$, greater stability $(-20.1 \mathrm{mV})$, drug content (96.34\%), and entrapment efficiency (94.4\%); invitro drug release data showed $94.04 \%$ of drug release sustained up to $12 \mathrm{hr}$ and followed the first order kinetics with non-fickian diffusion mechanism
Using $1 \% \mathrm{w} / \mathrm{w}$ carbopol 934 as a polymer gel base, plain gel (PG) and ethosomes loaded (E5G) gel were prepared by dispersion method. The cumulative percentage drug release of PG, E5G formulations were found to be $97.8 \%$ and $79.1 \%$ respectively at the end of $5 \mathrm{hr}$ and $12 \mathrm{hr}$. By comparison, E5G was found to be the best as it was able to sustain the release for about $12 \mathrm{hr}$ with a cumulative percentage release of about $79.1 \%$.

\section{References}

[1] B. Nagadevi, K.S. Kumar, P. Venkanna, et al., Formulation and characterisation of tizanidine hydrochloride loaded ethosomes patch. International Journal of Pharmacy and Pharmaceutical Sciences, 2014, 6(4): 199-205.

[2] M. Irfan, S. Verma, and A. Ram., Preparation and characterization of ibuprofen loaded transferosome as a novel carrier for transdermal drug delivery system. Asian Journal of Pharmaceutical and Clinical Research, 2012, 5(3): 162-165.

[3] G. Cevc, G. Blume, New highly effcient formulation of diclofenac for the topical, transdermal administration in ultradeformable drug carriers, transfersomes. Biochimica et Biophysica Acta, 2001, 1514: 191-205.

[4] S. Duangjit, P. Opanasopit, T. Rojanarata, et al., Characterization and in vitro skin permeation of meloxicam-loaded liposomes versus transfersomes. Journal of Drug Delivery, 2011, 2011: 418316.

[5] Preeti, M.S. Kumar, Development of celecoxib transfersomal gel for the treatment of rheumatoid arthritis. Indian Journal of Pharmaceutical and Biological Research, 2014, 2(2): 7-13.

[6] C. Fan, X. Li, Y. Zhou, et al., Enhanced topical delivery of tetrandrine by ethosomes for treatment of arthritis. BioMed Research International, 2013, 2013: 161943.

[7] R.G.S. Maheshwari, R.K. Tekade, P.A. Sharma, et al., Ethosomes and ultradeformable liposomes for transdermaldelivery of clotrimazole: A comparative assessment. Saudi Pharmaceutical Journal, 2012, 20: 161-170.

[8] X. Liu, H. Liu, J. Liu, et al., Preparation of a ligustrazine ethosome patchand its evaluation in vitro and in vivo. International Journal of Nano medicine, 2011, 6: 241247.

[9] R. Bhana, A. Verma, and S. Jain, Development and characterization of ethosomes bearing losartan potassium. International Journal of Pharmacy and Pharmaceutical Sciences, 2013, 5(1): 35-40.

[10] B. Sujitha, B. Krishnamoorthy, and M. Muthukumaran, Formulation and evaluation of piroxicam loaded ethosomal gel for transdermal delivery. Int $J$ Adv Pharm Gen Res, 2014, 2(1): 34-45.

[11] A.R. Rathore, H.Khambete and S. Jain., Preparation and characterization of repaglinide loaded ethosomal gel for the treatment of NIDDM. International Journal of Pharmaceutical \& Biological Archives, 2013, 4(2): 385390.

[12] S. Ghanbarzadeh, S. Aramil, Enhanced transdermal delivery of diclofenac sodium via conventional liposomes, ethosomes, and transfersomes. BioMed Research International, 2013, 2013: 616810.

[13] H.A. Benson, Transfersomes for transdermal drug delivery. Expert Opin. Drug Deliv., 2006, 3(6): 727-737.

[14] C. Hafer, R. Goble, P. Deering, et al., Formulation of 
interleukin-2 and interferon-alpha containing ultradeformable carriers for potential transdermal application. Anticancer Res., 1999, 19(2c): 1505-1507.

[15] C. Gregor, G. Dieter, S. Juliane, et al., Ultra-flexible vesicles, transfersomes, have an extremely low pore penetration resistance and transport therapeutic amounts of insulin across the intact mammalian skin. Biophysica Acta, 1998, 1368: 201-215.

[16] D.M. Sheo, A. Shweta, C.D. Ram, et al., Transfersomes - a novel vesicular carrier for enhanced transdermal delivery of stavudine: development, characterization and performance evaluation. J. Scientific Speculations and Res, 2010, 1(1): 30-36.

[17] J.R. Walve, S.R. Bakliwal, B.R. Rane, et al., Transfersomes: a surrogated carrier for transdermal drug delivery system. International Journal of Applied Biology and Pharmaceutical Technology, 2011, 2(1): 201-214.

[18] S. Pandey, M. Goyani, V. Devmurari, et al., Transferosomes: a novel approach for transdermal drug delivery. Der Pharmacia Letter, 2009, 1(2): 143-150.

[19] N.K. Jain. Advances in controlled and novel drug delivery (first edition). CBS Publishers and Distributers, New Delhi, 2001: 426-451.

[20] R. Patel, S.K. Singh, S. Singh, et al., Development and characterization of curcumin loaded transfersome for transdermal delivery. J. Pharm Sci. Res., 2009, 1(4): 7180.

[21] D.M. Sheo, A. Shweta, K.T. Vijay, et al., Enhanced transdermal delivery of indinavir sulfate via transfersomes. Pharmacie Globale (IJCP), 2010, 1(6): $1-7$.

Copyright $(2017$ Regunta Supraja, Abbaraju Krishna Sailaja. This is an open-access article distributed under the terms of the Creative Commons Attribution License, which permits unrestricted use, distribution, and reproduction in any medium, provided the original author and source are credited. 